\title{
Solar radiation and street temperature as function of street orientation. An analysis of the status quo and simulation of future scenarios towards sustainability in Bahrain
}

\author{
Dr. Joao Pinelo Silva, Assistant Professor Architecture
}

College of Engineering at University of Bahrain

\begin{abstract}
This paper discusses the contribution of street orientation towards the development of a comfortable microclimate for pedestrians in Bahrain. Increasing walkability is a global agenda to address issues such as a) transportation, b) energy consumption, c) health, and d) air pollution, all of which are topics of the sustainability agenda. Thermal comfort is one of the pre-requisites for walkability. In warm climates, this is a challenging goal.

Street design is paramount for pedestrian comfort in warm climates. The roles of street orientation and aspect ratio are of particular importance as they determine the intake of solar radiation into the urban canyon. We investigate the state of affairs in Bahrain, by measuring the frequency with which the street orientations E-W, N-S, NE-SW, and NW-SE, currently occur. Research suggests that the street orientation E-W presents the lesser performance for mitigating the effects of heat gain. The ideal grid orientation would, therefore, be N-S, and NE-SW - NW-SE, avoiding street segments with E-W orientation.

A countrywide analysis shows that E-W orientation accounts for the highest overall street length with $37 \%$. The second most frequent orientation is N-S (29\%), the best performer. NW-SE and NE-SW both have frequencies of only $17 \%$. Preference for a street grid with N-S, NW-SE, and NE-SW orientation would improve the thermal performance of streets and provide a continuous network of a comfortable pedestrian environment. We simulate two future scenarios based on avoiding new E-W streets, or not. We measure their potential reduction in thermal gain and conclude that a simple policy could reduce solar exposition in $40 \%$.
\end{abstract}

Keywords: Walkability, Pedestrian, Street orientation, Temperature, Street design, Street canyon 


\section{Introduction}

The global trend towards the development of a safe pedestrian infrastructure has been pursued for decades [1][2] as a way to encourage walkability, as it promotes street livability [3], local economic vitality [4], and social interaction [5]. More recently, the pursue to increase pedestrianism has been driven by significant public health concerns due to soaring levels of inactivity across the globe [6][7]. In response to global goals to reduce inactivity [8], urban planning policies have focused on increasing walking for transportation [9][10][11][12], which is leading to a reinvigorated pursue of a connected and attractive network of public space.

Progress in urban climatology and biometeorology in the last decade have created conditions for the development of studies of behavior in the urban context, which shown that outdoor activities are affected by the microclimate [13][14]. In regions where the weather can severely influence the use of outdoor environments, it is essential to mitigate its effects. This mitigation can be achieved by the manipulation of the microclimate at street level.

Due to their direct exposure to the weather, the manipulation of outdoor microclimates is more limited in scope and depth than that of indoor environments. For this reason, the creation of outdoor environments is challenging, and achieving the maximum mitigation of the climate implies joint planning and design towards that particular goal. To plan and design for particular microclimatic goals, planners and designers need to have baseline information on the effect of design solutions to the microclimate. The main design component with influence on microclimate is the solar orientation of streets. This work measures the country-wise overall practice up to date, establishing a baseline that could serve as a reference point for guiding future development.

\section{Outdoor thermal comfort}

Persistent high temperatures due to climate might seem impossible to overcome by passive means. However, the manipulation of the microclimate to increase the thermal comfort outdoors does not imply reducing the summer temperatures to the level of winter ones. Thermal comfort does not depend entirely on the physics of the environment, such as temperature or humidity, but on psychological aspects as well 
[15]. Preliminary research on outdoor thermal comfort suggested a significant discrepancy between an objective description of the thermal comfort (Predicted Mean Vote (PMV) [16], based on environmental physics) and the subjective description (Actual Sensation Vote) [17]. The discrepancy lead the authors to conclude that the evaluation of thermal comfort must not be limited to physical indicators but to include physiological and psychological ones [15] relative feeling of comfort is, therefore, to a certain extent, dependent on the larger thermal context. Studies show that even declared indoor comfort depends on the contextual outdoor temperatures. Rupp and colleagues found that participants reported equivalent levels of comfort when exposed to different indoor temperatures, responding to variations in the outdoor temperature, with higher levels of outdoor temperature affording the participants comfort indoors at higher temperatures [18]. The findings strongly suggest a sense of adaptation on the part of the user, which can bridge some magnitude of the shortcomings of passive (design-based) microclimate manipulations.

The literature on urban climatology and biometeorology does not prescribe high nor low thresholds for parameters such as temperature, as cut off points for the use of outdoor environments. Physiological differences between groups seem to have a bearing on temperature preferences and sensitivity [19][20][21][22]. However, these studies have focused on indoor environments and did not include very high temperatures. Nonetheless, it seems likely that some groups are more vulnerable to high temperatures than others. Knowledge of such details would be informative to the design of outdoor environments. While research carried out locally might eventually reveal more precise guidelines for exactly which temperatures outdoor pedestrian areas should aim to deliver, it is an undeniable fact that in warm climates, an influence at the level of the microclimate is desirable.

\section{The urban canyon - street}

Climate physics are closely related to latitude, due to the effect that this has on the exposition to solar radiation. The impact of the climate on the microclimate is therefore studied at the regional level. The dulling of properties of the climate, such as temperature, can be achieved through the design of the built environment, namely through the manipulation of direct sun exposure. The systematic study of the impact 
of design features on the microclimate provides planners and designers with valuable information to make goal-oriented design decisions.

The streets make up for most of the urban public space used by pedestrians. Two properties of street design have been shown to have significant impact on the microclimate: a) street orientation, the relation of the street to the sun path, commonly represented by the cardinal directions; b) aspect-ratio, the proportion between the height of the buildings and the distance between them (width of the street). Such characteristics are at the genesis of any urban design, and, to a certain extent, depend on urban planning, and consequently, make a useful starting point for the investigation of local conditions. Street orientation is of particular interest because it is hardest to change after it has been built, while the ratio can be altered through the redesign of individual buildings.

Due to the geometrical and microclimatic similarities with canyons, urban streets are commonly described as urban canyons, canyons, or street canyons, after [23]. These are important spatial units for the analysis of the energy input, partitioning and output of a structure that is repeated throughout a city [23]. Since the exposure influences the amount of energy input, the study of typical exposures is necessary for a comprehensive documentation of the thermal behavior of each configuration. In the absence of a local study, we use as reference one study completed in Ghadir, Tunisia, at a latitude of $32.40 \mathrm{~N}, 3.80 \mathrm{E}$ [24] approximately six degrees of latitude North of Bahrain $\left(26.13^{\circ} \mathrm{N}, 50.35^{\circ} \mathrm{E}\right)$. Shading as a design strategy to mitigate extreme heat has been confirmed by [25] and [26].

While the solar gain of one street contributes to its own overheating, the citywide sum of the thermal gain of individual street canyons contributes to raising the heat of the area, contributing to the urban heat island effect, as described by [27]. The effect results in the city having higher temperatures than surrounding non-urbanized areas. A perverse consequence of this effect is reached when the temperature is raised to a level that leads to the use of active cooling methods such as air conditioners. The motors of such equipment generate heat to produce cool. While the cold air is fed to indoor environments, the hot air is dissipated outdoors, thus contributing to a further increase of the temperature within the canyons. 


\section{The Orientation of Street Canyons}

Ali-Toudert and Mayer [24] show through numerical analysis of digital modeling of the microclimate of street canyons that the orientation of the canyon significantly shapes thermal gain, thus influencing air temperature at 1.2 meters from the ground (the pedestrian domain). The model is based on a typical summer day (1st August) in Ghardia, Algeria, approximately $6^{\circ}$ North of Bahrain. The climate is hot and dry (Saharan). The simulation duration is from 7:00 to 20:00. The model had a spatial resolution of one meter horizontally, and two meters vertically. The results report that the highest differences between orientation are felt in the afternoon (around 15:00), and are only significant between 9:00 and 19:00. As the aspect ratio increases, East-West (E-W) streets tend to be warmer than North-South (N-S) streets, due to their longer exposure to solar radiation. Overall, the results show that the most favorable orientation regarding thermal comfort is N-S, and the least comfortable E-W, for their longer periods of exposure to solar radiation. The intermediate orientations Northeast-Southwest (NE-SW), and Northwest-Southeast (NW-SE), present equivalent and intermediate levels of comfort, but are noticeably different from E-W streets [24] by offering lower temperatures and smaller duration of peak exposure.

E-W streets with low aspect ratio present PET patterns with extremely high values for over eight hours per day. Furthermore, the increase of height/width ratio to mitigate heat gain in E-W orientations is extremely limited [24, p.102]. Comparatively, $\mathrm{N}-\mathrm{S}$ streets with equivalent aspect ratios present lower temperatures in general and a smaller duration of peak temperatures. On streets with an aspect ratio $\geq 2$, the peak PET temperature is reduced and only occurs for 2 hours, around noon. Streets with intermediate orientations (NE-SW, NW-SE), present (in equivalent aspect ratios), a compromise between the two main orientations (N-S and E-W), with lower peak temperatures and shorter length of about 4 hours.

Overall, the analysis of the orientation makes sense in isolation only at an aggregate level, as a way to measure the potential to increase comfort at street level in the country's portfolio. The real solar gain highly depends on width to height ratio. At very low ratios (approx. 0.5) the differences in solar gain between orientations are minimal. However, the as the ratio increases, the reduction in solar gain increases significantly in N-S and NE-SW and NW-SE, while it is barely noticeable on E-W streets. Current orientation of segments with an aspect ratio $<2$ is a measurement of 
the dormant potential to more comfortable streets. For segments with aspect ratio $\geq$ 2 , the orientation reflects the current intake of solar radiation.

According to the results discussed above, the ideal orientation would be to use would be N-S, which is roughly the bearing of the island of Bahrain, and is likely to be naturally frequent. Nonetheless, grids tend to be orthogonal, and therefore, E-W streets, which are the poorest thermal performers, would complement N-S ones. The optimal solution seems likely to be a mix of N-S streets with a grid expanding NESW and NW-SE. Furthermore, a crucial feature of a pedestrian network is continuity. A grid with N-S and E-W elements would have its continuity challenged by the lack of thermal comfort in E-W streets, even if these had high aspect ratios. Figure 1 illustrates the four street orientations discussed and the binning factor used to categorize the current network of Bahrain, discussed below.

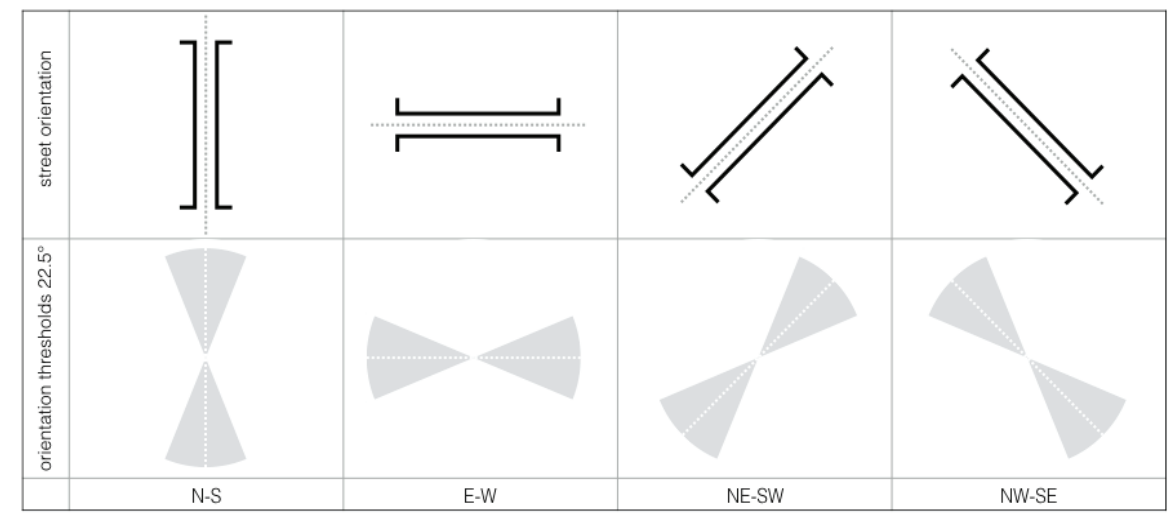

Figure 1 - Orientation of street canyons and the binning thresholds used for the categorization of the segments in the case studies of Bahrain and Manhattan N.Y.

\section{Site Climate}


Bahrain, the main island of the archipelago Kingdom of Bahrain, has an area of 572 square kilometers. The island measures 48 kilometers from north to south, and 16 kilometers east to west. The highest point is Jabal al Dukham at 134 meters above the mean sea level. The largest city is the capital Manama, which originally developed around the seaport, lays just above sea level. The climate presents pleasant temperatures during the largest part of the year, with the minimum average low temperature of $14{ }^{\circ} \mathrm{C}$ Celsius taking place in January. However, from May through September, the temperatures are higher, and in the summer temperatures in the afternoon frequently reaching the high forties. The average temperature for the months of May through September is above $30^{\circ} \mathrm{C}$ Celsius $\left(86^{\circ} \mathrm{F}\right.$ Fahrenheit), with the average of the minimum temperature during June through September being over $30^{\circ} \mathrm{C}\left(86^{\circ} \mathrm{F}\right.$ Fahrenheit), as illustrated in Table 1.

\begin{tabular}{|c|c|c|c|c|c|c|c|c|c|c|c|c|}
\hline & Jan. & Feb. & Mar. & Apr. & May & Jun. & Jul. & Aug. & Sep. & Oct. & Nov. & Dec. \\
\hline Average High Temperature $\left({ }^{\circ} \mathrm{C}\right)$ & 20.3 & 22.4 & 26.1 & 30.7 & 36.9 & 39.0 & 39.9 & 39.8 & 37.9 & 33.7 & 27.7 & 22.4 \\
\hline Average Temperature $\left({ }^{\circ} \mathrm{C}\right)$ & 17.2 & 18.5 & 21.7 & 26.2 & 32.0 & 34.6 & 35.6 & 35.5 & 33.7 & 30.0 & 24.6 & 19.3 \\
\hline Average Low Temperature $\left({ }^{\circ} \mathrm{C}\right)$ & 14.4 & 15.5 & 18.5 & 22.8 & 28.3 & 31.1 & 32.2 & 32.2 & 30.4 & 26.9 & 21.9 & 16.6 \\
\hline Maximum Relative Humidity (\%) & 88 & 87 & 84 & 81 & 78 & 77 & 80 & 82 & 85 & 86 & 85 & 87 \\
\hline Minimum Relative Humidity (\%) & 57 & 55 & 47 & 42 & 39 & 39 & 40 & 44 & 44 & 47 & 52 & 56 \\
\hline Precipitation (mm) & 14.6 & 1.5 & 1.9 & 5.1 & 0.4 & 0.0 & 0.0 & 0.0 & 0.0 & 0.0 & 10.2 & 14.5 \\
\hline
\end{tabular}

The relative humidity is high throughout the year. The mean daily maximum relative humidity reaches the annual highest value of $88 \%$ in January, and the minimum of $77 \%$ in June. The mean daily minimum relative humidity reaches a maximum of $57 \%$ in January and a minimum of $39 \%$ in May and June. The precipitation is irregular and low, with a maximum of approximately $15 \mathrm{~mm}$ in December and January, and 0mm from June through October (Table 1).

\section{Methodology}

We use the segment map of Bahrain, which is similar to a road-center-line map, except for the fact that it includes pedestrian areas and not only vehicular ones, and it is made exclusively of straight segments, as opposed to including arcs [28]. Therefore such map presents nodes at every change in direction, making it a suitable candidate for the measurement of the orientation of each component of the street 
network. For comparison, we use the segment of Manhattan (New York) to demonstrate an alternative balance between the main four cardinal orientations (Figure 2). The maps were drawn on a Geographic Information Systems (GIS) software package, and the azimuth of each street segment measured.

The data was then exported to a statistical analysis package [29] where the analysis is processed and charts created [30]. We quantify each orientation category in two ways: a) the total number of street segments, and b) the total sum of street

length. Remove lines with length less than $30 \mathrm{~m}$, as they are not likely to represent formed street canyons.
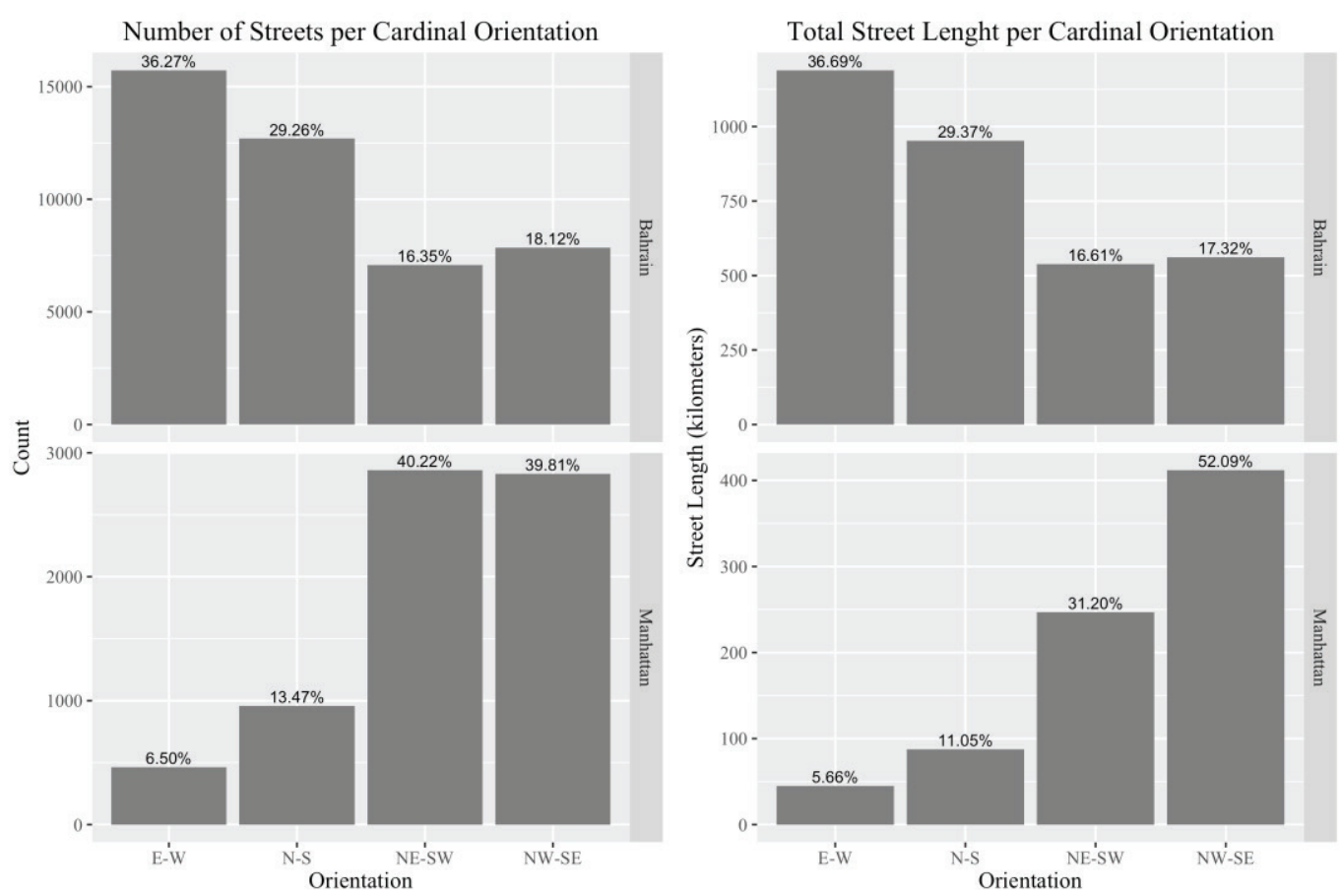

Figure 2 - The relative proportions of each orientation towards the number of streets and total street length in Bahrain and Manhattan present opposite trends.

Based on the spatial and temporal variation of the physiologically equivalent temperature PET at 1.2 meters above ground, for the aspect ratio (height/width) 2, 
as calculated per [24], we calculate the thermal coefficient of each street orientation (TCSO). The TCSO is calculated by multiplying the time interval of duration of PET over $42^{\circ} \mathrm{C}$ (107.6 Fahrenheit) by the maximum temperature reached. The units of the TCSO are hours per degrees Celsius. The TCSO for each orientation are shown in Table 2.

\begin{tabular}{lcccc}
\multicolumn{4}{c}{ Table 2. Thermal Coefficient of Street Orientation based on Ali-Toudert and Mayer (2006) } \\
\hline Orientation & Interval PET $>\mathbf{4 2}^{\circ} \mathbf{C}$ (time) & Duration (hours) & Max. PET $\left({ }^{\circ} \mathbf{C}\right)$ & TCSO \\
E-W & $09: 00$ to $18: 00$ & 9.00 & 68 & 612 \\
N-S & $11: 00$ to $15: 00$ & 4.00 & 56 & 224 \\
NE-SW & $11: 30$ to $16: 00$ & 4.50 & 66 & 297 \\
NW-SE & $10: 15$ to $16: 30$ & 6.25 & 62 & 388 \\
\hline
\end{tabular}

As expected, the TCSO is significantly larger for the E-W orientation. We calculate the current 'cost' of each orientation by multiplying the total street length by the corresponding TCSO. We then simulate two alternative scenarios for the future, when the network is doubled. Figure 3 illustrates the potential impact on the growth of TCSO for the same total street length. Scenario 1 (Future non Regulated) describes a situation that can be expected if no regulation addresses the choice of street orientation. Scenario 2 describes a future where a planning policy determines that no streets should be made with orientation E-W. In this scenario, the other types grow by the same proportion (2.33333). The potential positive effect is noticeable by the lesser increase of TCSO (approximately less 40\%) in for the regulated future scenario. The increase in TCSO for double the network length would represent an increase of $200 \%$, to 2637072 Celsius per Hour per Kilometre. The same increase in the length of the network, guided by a policy that would prevent the creation of EW streets, would increase the TSCO to 2106372 (160\%)(see Figure 3).

\section{Results, Discussion and Conclusion}

The analysis is summarised in Figure 2, which shows that the prevailing orientation of streets in Bahrain is E-W, with $36 \%$ of the total number of street segments, and $37 \%$ of the total street length. The second prevailing direction is N-S, with $29 \%$ of both the number of street segments of total street length. The third prevailing direction is NE-SW with $16 \%$ street segments and $17 \%$ of total street length. The least frequent direction is NW-SE with $18 \%$ street segments and $17 \%$ total street 
length. Cumulatively, the less desired orientations (E-W and N-S) is over represented with $66 \%$ of the total number of streets segments and of the total street length; while the desired orientations are under represented with $34 \%$.

In regions with harsh climatic conditions, the manipulation of the microclimate is a crucial element towards creating favourable conditions for the use of outdoor spaces, complementing an appropriate land use mix and infrastructure such as sidewalks and amenities. The cardinal orientation of street canyons is of paramount importance because of its passive role on solar intake, and also its perpetual character. Less permanent features being, for example, aspect ratio, building materials or vegetation.

The results show a clear tendency for streets to follow N-S and E-W orientation, rather than the desired NE-SW and NW-SE. The situation implies that the current situation in Bahrain is neither neutral (equally favouring all orientations), nor towards the desired orientation, but the opposite. This is likely to be due to the oblong shape, and orientation the island itself, the longest axis being a few degrees off north. The tendency to follow the E-W and N-S directions when designing infrastructure aims at shortening the distance between the geographic extremes. However, such concern, though legitimate when considering the largest distances, could be avoided at local scale, in the design of the complementary network, such as within cities and neighbourhoods. Regulating street orientation through policy could significantly decrease the solar gain of street canyons. The aggregate effect of such policy would be a reduction of solar intake of approximately $40 \%$, as illustrated in Figure 3. 


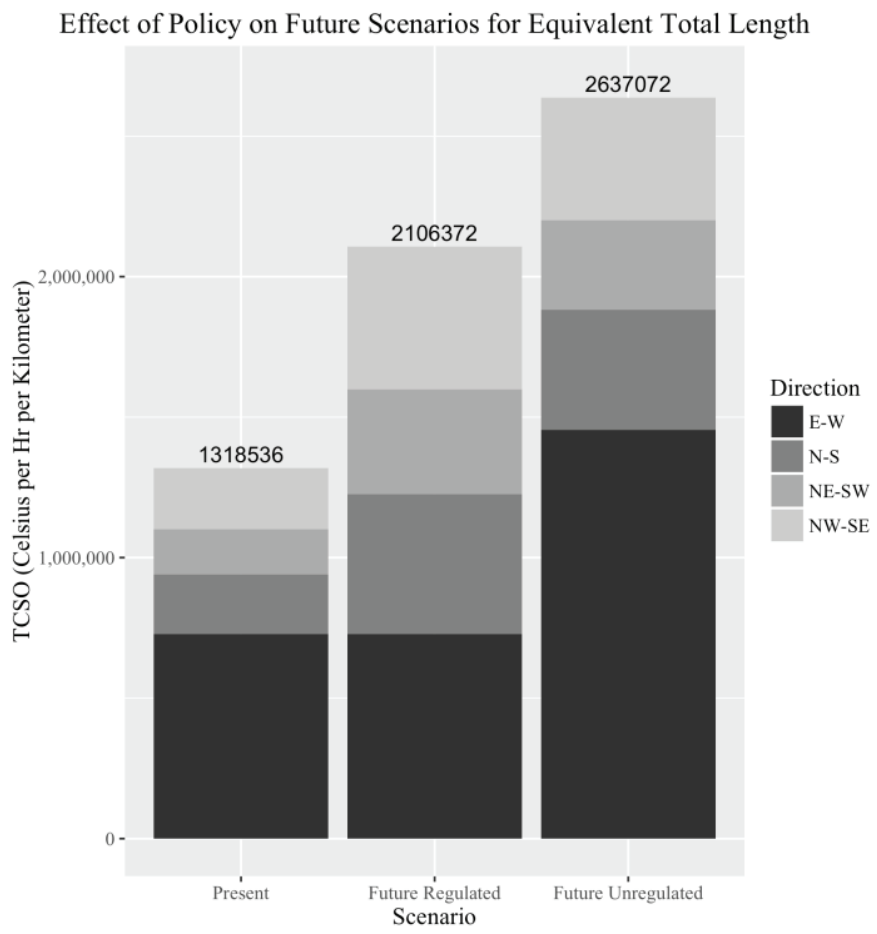

Figure 3 -

Illustration of current exposure to current high temperatures and two potential future scenarios; with regulated and unregulated street orientation.

Inverting the current balance between orientations would significantly increase the baseline potential for reaching thermal comfort at the street level, thus creating a basic condition for the development of pedestrianism. Such conditions would impact the reliance on motor vehicles for short distances and generate a local distribution network for public transport. As a consequence, motorized traffic should diminish, bringing down air pollution. The population would have more opportunities to walk for transportation, thus increasing levels of physical activity, and therefore decreasing public health problems.

Reaching the maximum potential for thermal street comfort would involve concerted efforts, starting with adoption the desired orientations (NE-SW and NW-SE) as default, followed by other design principles. Further to street design, a strategy for the spatial distribution of land use, could diminish the dependence on longer trips. Furthermore, a marketing campaign to sensitize the population to the benefits of walking would fix an eventual stigma in favour of the use of private transportation. 
A limitation of the application of a favourable street orientation is that its effects are only felt on aspects ratios larger than 0.5 [24], [31]. Therefore, they do not constitute an advantage on residential neighbourhoods with lower aspect ratios, as is the case with houses, unless the buildings are placed right on the street, with small set-backs, no front gardens, and without spacing in-between properties, resembling multi-story housing.

The suggestion that air temperature might be more sensitive to the aspect ratio than to street orientation [24,p.99], suggests that re-profiling streets towards increasing their aspect ratio (height/width $\geq 2$ ) could lead to a thermal comfort increase on existing streets. However, the efficiency of aspect ratio on streets with E-W orientation is very limited [24,p.102].

Ali-Toudert and Mayer [24] also conclude that, based on their results, air temperature might be more sensitive to the aspect ratio than to street orientation [24,p.99]. This finding suggests that it might be worth studying the potential impact of a policy that regulates the height/width ratio of new streets.

\section{Study Limitations}

Due to the lack of better data, the study assumes that the thermal performance of the canyon orientation/ratio in Bahrain $\left(26.13^{\circ} \mathrm{N}, 50.35^{\circ} \mathrm{E}\right)$ is similar to that on Ghardaia, Algeria $\left(32.40^{\circ} \mathrm{N}, 3.80^{\circ} \mathrm{E}\right)$, which is the, geographically closer, numerical study made [24]. The difference consisting on approximately six degrees of latitude. A local detailed numerical analysis of the thermal behaviour of street canyons in Bahrain as a function of orientation and aspect ratio, considering local climatic conditions such as temperature, wind and humidity, would make it possible to clearly estimate the impact of street orientation, and its cumulative effect.

\section{Funding}


Deanship for Scientific Research, University of Bahrain, Project 12/2014.

\section{References}

[1] APPLEYARD, D., GERSON, M. S., LINTELL, M., ÊTATS, U. \& FEDERAL HIGHWAY, A. 1976. Liveable urban streets managing auto traffic in neighborhoods : final report : prepared for Federal Highway Administration, Department of Transportation, Washington, U.S. Dept. of Transportation, Federal Highway Administration : for sale by the Supt. of Docs., U.S. Govt. Print. Off.

[2] GEHL, J. \& GEMZØE, L. 1999. Public spaces - public life : Copenhagen 1996, Copenhagen, Danish Architectural Press.

[3] GEHL, J. 2006. Life between the buildings : using public space, Copenhagen, Danish Architectural Press.

[4] MARSHALL, S. 2005. Streets and patterns : the structure of urban geometry, London : Spon.

[5] HILLIER, B. \& HANSON, J. 1984. The social logic of space, Cambridge : Cambridge University Press.

[6] JEON, C. Y., LOKKEN, R. P., HU, F. B. \& VAN DAM, R. M. 2007. Physical Activity of Moderate Intensity and Risk of Type 2 Diabetes: A systematic review. Diabetes Care, 30, 744752.

[7] LEE, I. M., SHIROMA, E. J., LOBELO, F., PUSKA, P., BLAIR, S. N. \& KATZMARZYK, P. T. 2012. Impact of Physical Inactivity on the World's Major Non-Communicable Diseases. Lancet, 380, 219-229.

[8] WORLD HEALTH ORGANIZATION, 2013, Global Action Plan for the Prevention and control of Noncommunicable Diseases 2013-2020. WHO Press, Geneva.

[9] TRANSPORT FOR LONDON, L. 2005. Improving Walkability. London, England.

[10] LAND TRANSPORT NEW ZEALAND, Z. 2007. Pedestrian Planning and Design Guide. Wellington: New Zealand.

[11] EWING, R. \& CERVERO, R. 2010. Travel and the Built Environment. Journal of the American Planning Association, 76, 265-294.

[12] RYUS, P. 2014. Guidebook on pedestrian and bicycle volume data collection, Washington, DC, Transportation Research Board of the National Academies.

[13] ZACHARIAS, J., STATHOPOULOS, T. \& WU, H. 2004. Spatial Behavior in San Francisco's Plazas: The Effects of Microclimate, Other People, and Environmental Design. Environment and Behavior, 36, 638-658. 
[14] ALJAWABRA, F. \& NIKOLOPOULOU, M. 2010. Influence of hot arid climate on the use of outdoor urban spaces and thermal comfort: Do cultural and social backgrounds matter? Intelligent Buildings International, 2, 198-217.

[15] NIKOLOPOUlOU, M. \& STEEMERS, K. 2003. Thermal comfort and psychological adaptation as a guide for designing urban spaces. Energy and Buildings, 35, 95-101.

[16] FANGER, P. O. 1982. Thermal comfort : analysis and applications in environmental engineering, Malabar, Fla., R.E. Krieger Pub. Co.

[17] NIKOLOPOULOU, M. A. B., NICK AND STEEMERS, KOEN 2001. Thermal comfort in outdoor urban spaces: understanding the human parameter. Solar energy, 70, 227-235.

[18] RUPP, R. F., VÁSQUEZ, N. G. \& LAMBERTS, R. 2015. A review of human thermal comfort in the built environment. Energy and Buildings, 105, 178-205.

[19] WANG, Z. 2006. A field study of the thermal comfort in residential buildings in Harbin. Building and Environment, 41, 1034-1039.

[20] KARJALAINEN, S. 2007. Gender differences in thermal comfort and use of thermostats in everyday thermal environments. Building and Environment, 42, 1594-1603.

[21] KARJALAINEN, S. 2012. Thermal comfort and gender: a literature review. Indoor Air, 22, 96-109.

[22] TUNG, C.-H., CHEN, C.-P., TSAI, K.-T., KÁNTOR, N., HWANG, R.-L., MATZARAKIS, A. \& LIN, T.-P. 2014. Outdoor thermal comfort characteristics in the hot and humid region from a gender perspective. International journal of biometeorology, 58, 1927-1939\%00020-7128.

[23] NUNEZ, M. \& OKE, T. R. 1977. The Energy Balance of an Urban Canyon. Journal of Applied Meteorology, 16, 11-19.

[24] ALI-TOUDERT, F. \& MAYER, H. 2006. Numerical study on the effects of aspect ratio and orientation of an urban street canyon on outdoor thermal comfort in hot and dry climate. Building and Environment, 41, 94-108.

[25] MAYER, H. \& HÖPPE, P. 1987. Thermal comfort of man in different urban environments. Theoretical and Applied Climatology, 38, 43-49.

[26] MAYER, M. 1993. Urban bioclimatology. Experientia, 49, 957.

[27] HOWARD, L. F. R. S. 1818. The climate of London, deduced from Meteorological observations, made at different places in the neighbourhood of the metropolis, London.

[28] TURNER, A. 2007. From axial to road-centre lines: a new representation for space syntax and a new model of route choice for transport network analysis. Environment and Planning BPlanning \& Design, 34, 539-555.

[29] R Core Team (2016). R: A language and environment for statistical computing. R Foundation for Statistical Computing, Vienna, Austria. URL https://www.R-project.org/ 
[30] H. WICKAM. ggplot2: Elegant Graphics for Data Analysis. Springer-Verlag New York, 2009.

[31] KARIMINIA, S., AHMAD, S. S. \& SABERI, A. 2015. Microclimatic Conditions of an Urban Square: Role of Built Environment and Geometry. Procedia - Social and Behavioral Sciences, 170, 718-727. 